Supporting Information for

\title{
Ion-Selective Optical Nanosensors based on Solvatochromic \\ Dyes of Different Lipophilicity: From Bulk Partitioning to Interfacial Accumulation
}

\author{
Xiaojiang Xie*, Istvan Szilagyi, Jingying Zhai, Lu Wang and Eric Bakker* \\ Department of Inorganic and Analytical Chemistry, University of Geneva, CH1211, Geneva, \\ Switzerland \\ *xiaojiang.xie@unige.ch \\ * eric.bakker@unige.ch
}

\section{Table of Contents}

Synthetic routes and structural information for the SDs

S-2 to S-8

Supplementary Figures S1 and S2

S-9

Supplementary Figures S3 and S4

S-10

Appendix 1. Theoretical response for nanosensors containing water soluble SDs and influence of nanosensor loading (dilution effect)

S-11 to $S-13$

Appendix 2. Theoretical response for nanosensors containing lipophilized SDs S-14 to S-15

FRET efficiency $(E)$, the overlap integral $(J)$, Förster distance $\left(R_{0}\right)$ and distance between adjacent donor Lumogen Red and acceptor SD $2\left(R_{\mathrm{DA}}\right)$.

S-16

References

S-16 
Synthetic Routes for SD 1, 2, 3 and 4:
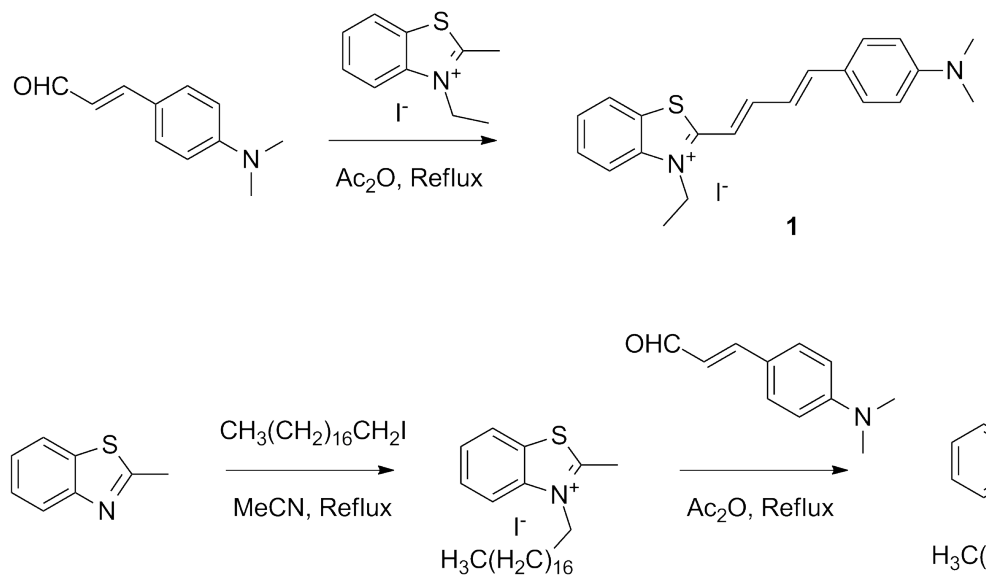

$2 a$

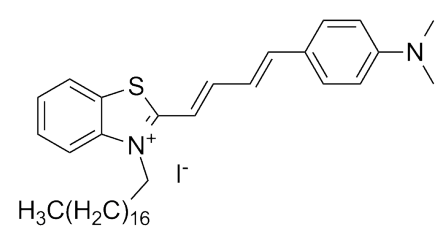

2
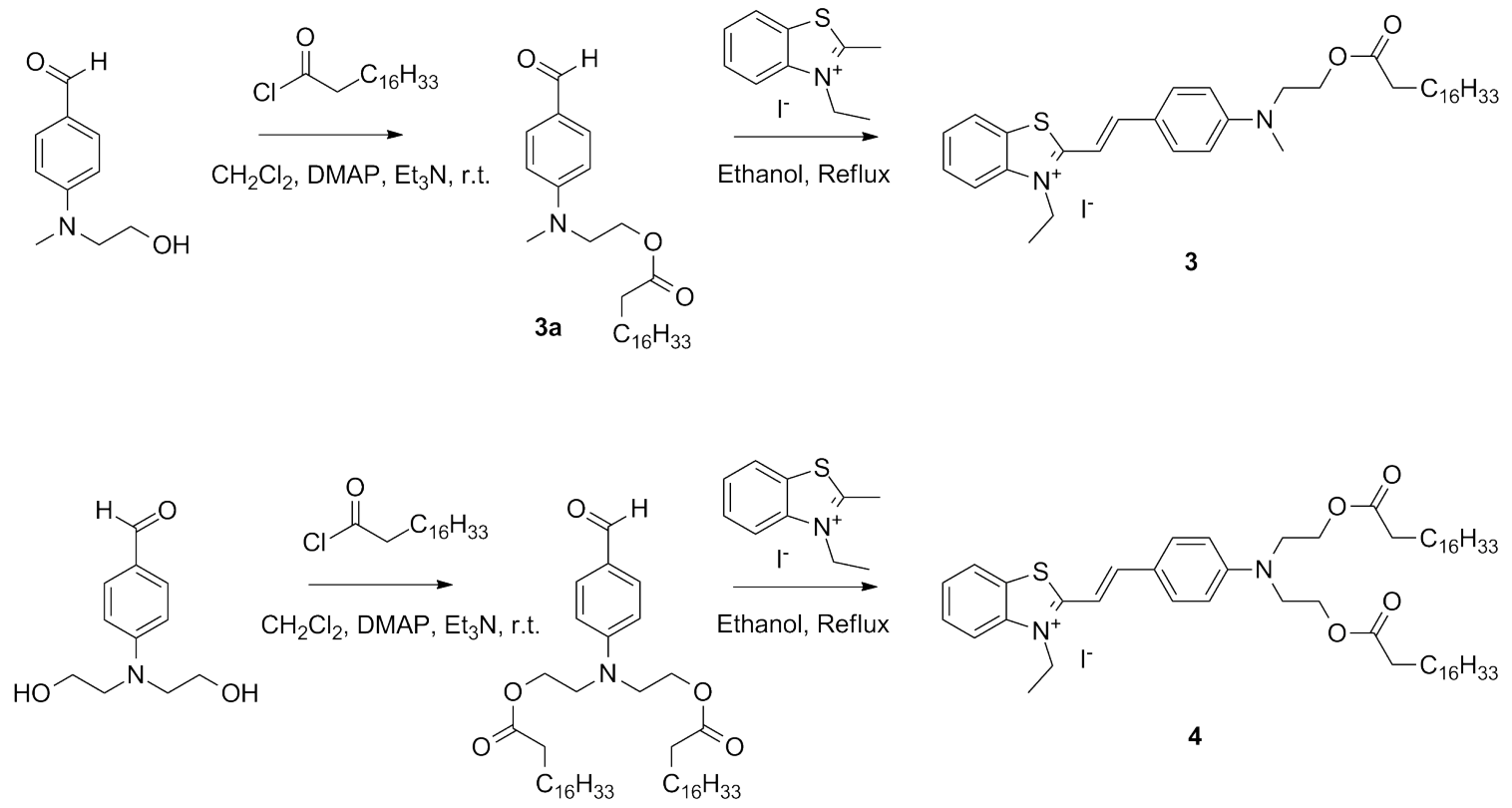


\section{Synthetic Procedure:}

\section{2-((1E,3E)-4-(4-(dimethylamino)phenyl)buta-1,3-dien-1-yl)-3-ethylbenzo[d]thiazol-3-ium iodide (1):}

A mixture of 3-ethyl-2-methylbenzothiazolium iodide $(305 \mathrm{mg}, 1 \mathrm{mmol})$, 4(dimethylamino)cinnamaldehyde $(176 \mathrm{mg}, 1 \mathrm{mmol})$ and acetic anhydride $(20 \mathrm{ml})$ was refluxed for $20 \mathrm{~min}$, then poured into a warm solution of sodium iodide $(0.01 \mathrm{M})$ in water $(20 \mathrm{ml})$. The precipitated product was filtered, washed with water and recrystallized from methanol to give a purple powder (250 mg, yield: $54 \%$ ). 'H NMR (d-DMSO): $\delta / \mathrm{ppm}$ : 8.13-8.06 $(1.5 \mathrm{H}, \mathrm{m}), 7.72-7.52$ $(7.5 \mathrm{H}, \mathrm{m}), 7.32(1 \mathrm{H}, \mathrm{s}), 6.72-6.70(\mathrm{~J}=8 \mathrm{~Hz}, 2 \mathrm{H}, \mathrm{d}), 4.94-4.88(\mathrm{~J}=8 \mathrm{~Hz}, 2 \mathrm{H}, \mathrm{q}), 3.12(6 \mathrm{H}, \mathrm{s}), 1.69-1.65$ $(\mathrm{J}=8 \mathrm{~Hz}, 3 \mathrm{H}, \mathrm{t}) \mathrm{m} / \mathrm{z}(\mathrm{ESI}): 335.3$

\section{2-methyl-3-octadecylbenzo[d]thiazol-3-ium iodide (2a):}

A mixture of 2-methylbenzothiazole (1.5 g, $10 \mathrm{mmol})$, 1-iodooctadecane $(3.8 \mathrm{~g}, 10 \mathrm{mmol})$ and 10 $\mathrm{mL}$ acetonitrile was refluxed for $12 \mathrm{~h}$. After cooling to room temperature, the solidified crude product was suspended in tetrahydrofuran and precipitation was improved by adding diethyl ether. The crude product was collected, washed several times with diethyl ether and used directly. (1.1 g, yield: $21 \%$ ) 'H NMR (CDCl): $\delta /$ ppm: $7.97-7.95(\mathrm{~J}=8 \mathrm{~Hz}, 1 \mathrm{H}, \mathrm{d}), 7.84-7.82(\mathrm{~J}=8 \mathrm{~Hz}$, $1 \mathrm{H}, \mathrm{d}), 7.47-7.43(\mathrm{~J}=8 \mathrm{~Hz}, 1 \mathrm{H}, \mathrm{t}), 7.37-7.33(\mathrm{~J}=8 \mathrm{~Hz}, 1 \mathrm{H}, \mathrm{t}), 3.75-3.70(\mathrm{~J}=8 \mathrm{~Hz}, 2 \mathrm{H}, \mathrm{q}), 2.85(3 \mathrm{H}, \mathrm{s})$, 1.40-1.23 (32H, m), 0.90-0.86 (J=8 Hz, 3H, t) m/ z (ESI): 402.7

\section{2-((1E,3E)-4-(4-(dimethylamino)phenyl)buta-1,3-dien-1-yl)-3-octadecylbenzo[d]thiazol-3-ium iodide (2):}

A mixture of 2-methyl-3-octadecylbenzo[d]thiazol-3-ium iodide (2a) (265 mg, $0.5 \mathrm{mmol}$ ), 4(dimethylamino)cinnamaldehyde $(122 \mathrm{mg}, 0.7 \mathrm{mmol})$ and acetic anhydride $(10 \mathrm{ml})$ was refluxed for $20 \mathrm{~min}$, then poured into a warm solution of sodium iodide $(0.01 \mathrm{M})$ in water $(20 \mathrm{ml})$. The precipitated product was filtered, washed with water and recrystallized from ethanol to give a dark purple powder $(210 \mathrm{mg}$, yield: $61 \%)$. 'H NMR $\left(\mathrm{CDCl}_{3}\right)$ : $\delta / \mathrm{ppm}$ : 8.10-8.08 $(1 \mathrm{H}, \mathrm{d}), 7.95-7.89$ $(1 \mathrm{H}, \mathrm{m}), 7.73-7.65(3 \mathrm{H}, \mathrm{m}), 7.57-7.50(4 \mathrm{H}, \mathrm{m}), 7.35-7.31(1 \mathrm{H}, \mathrm{d}), 6.64-6.61(2 \mathrm{H}, \mathrm{d}), 4.81-4.78(2 \mathrm{H}, \mathrm{t})$ $3.06(6 \mathrm{H}, \mathrm{s}), 1.94-1.92(2 \mathrm{H}, \mathrm{m}), 1.54-1.23(30 \mathrm{H}, \mathrm{m}), 0.89-0.86(\mathrm{~J}=8 \mathrm{~Hz}, 3 \mathrm{H}, \mathrm{t}) \mathrm{m} / \mathrm{z}(\mathrm{ESI}): 559.5$

\section{2-((4-formylphenyl)(methyl)amino)ethyl stearate (3a):}

To a solution of N-methyl-N-(2-hydroxyethyl)-4-aminobenzaldehyde (554 mg, $3.1 \mathrm{mmol}), 450 \mu \mathrm{L}$ of $\mathrm{Et}_{\mathrm{N}} \mathrm{N}, 5 \mathrm{mg}$ of DMAP in $30 \mathrm{~mL}$ dichloromethane was gradually added a solution of stearoyl chloride ( $900 \mathrm{mg}, 3 \mathrm{mmol}$ ) in $5 \mathrm{~mL}$ of dichloromethane. The reaction was kept overnight and then the diluted with $100 \mathrm{~mL}$ of dichloromethane, washed with water $(100 \mathrm{~mL}, 3$ times). The crude product after removal of solvent was purified with silica gel column chromatography (n-hexane : ethyl acetate $=3: 1$ ) to give $1.2 \mathrm{~g}$ of yellowish solid. (yield: $90 \%) \mathrm{H} \mathrm{NMR}\left(\mathrm{CDCl}_{3}\right): \delta / \mathrm{ppm}: 9.78$ $(1 \mathrm{H}, \mathrm{s}), 7.77-7.75(2 \mathrm{H}, \mathrm{d}), 6.80-6.78(2 \mathrm{H}, \mathrm{d}), 4.32-4.29(2 \mathrm{H}, \mathrm{t}), 3.74-3.71(2 \mathrm{H}, \mathrm{t}), 3.12(3 \mathrm{H}, \mathrm{s}), 2.28-2.24$ $(\mathrm{J}=8 \mathrm{~Hz}, 2 \mathrm{H}, \mathrm{t}), 1.28-1.27(28 \mathrm{H}, \mathrm{m}), 0.93-0.89(\mathrm{~J}=8 \mathrm{~Hz}, 3 \mathrm{H}, \mathrm{t}) \mathrm{m} / \mathrm{z}$ (ESI): 445.6

\section{(E)-3-ethyl-2-(4-(methyl(2-(stearoyloxy)ethyl)amino)styryl)benzo[d]thiazol-3-ium iodide (3):}

A mixture of 3-ethyl-2-methylbenzothiazolium iodide (152 $\mathrm{mg}, 0.5 \mathrm{mmol})$ and 2-((4formylphenyl)(methyl)amino)ethyl stearate (3a)(230 mg, $0.5 \mathrm{mmol})$ in $10 \mathrm{~mL}$ ethanol was 
refluxed for $6 \mathrm{~h}$. After cooling to room temperature, the solid precipitated was filtered and recrystallized in ethanol to give $300 \mathrm{mg}$ of dark red powder. (yield: $31 \%$ ) $\mathrm{H} \mathrm{NMR}\left(\mathrm{CDCl}_{3}\right)$ : $\delta /$ ppm: 8.08-8.05 (3H, d), 7.89-7.88 (2H, d), 7.73-7.67 (2H, m), 7.62-7.58 $(1 \mathrm{H}, \mathrm{t}), 6.73-6.71(\mathrm{~J}=8 \mathrm{~Hz}, 2 \mathrm{H}$, d), 5.12-5.07 (J=8 Hz, 2H, q), 4.27-4.25 (J=4 Hz, 2H, t) 3.71-3.66 (J=4 Hz, 2H, t), 3.08 (3H, s),2.29 $2.26(\mathrm{~J}=8 \mathrm{~Hz}, 2 \mathrm{H}, \mathrm{t}), 1.59-1.57(\mathrm{~J}=8 \mathrm{~Hz}, 3 \mathrm{H}, \mathrm{t}), 1.57-1.23(30 \mathrm{H}, \mathrm{m}), 0.89-0.86(\mathrm{~J}=8 \mathrm{~Hz}, 3 \mathrm{H}, \mathrm{t}) \mathrm{m} / \mathrm{z}(\mathrm{ESI})$ : 605.7

\section{((4-formylphenyl)azanediyl)bis(ethane-2,1-diyl) distearate (4a):}

To a solution of 4-[N,N-bis(2-hydroxyethyl)amino]benzaldehyde (210 mg, $1 \mathrm{mmol}), 150 \mu \mathrm{L}$ of $\mathrm{Et}_{\mathrm{s}} \mathrm{N}, 5 \mathrm{mg}$ of DMAP in $30 \mathrm{~mL}$ dichloromethane was gradually added a solution of stearoyl chloride ( $605 \mathrm{mg}, 2 \mathrm{mmol}$ ) in $5 \mathrm{~mL}$ of dichloromethane. The reaction was kept overnight and then the diluted with $100 \mathrm{~mL}$ of dichloromethane, washed with water $(100 \mathrm{~mL}, 3$ times). The crude product after removal of solvent was purified with silica gel column chromatography (n-hexane : ethyl acetate $=3: 1$ ) to give $680 \mathrm{mg}$ of yellowish solid. (yield: $92 \%) \mathrm{H} \mathrm{NMR}\left(\mathrm{CDCl}_{3}\right): \delta / \mathrm{ppm}: 9.76$ $(1 \mathrm{H}, \mathrm{s}), 7.77-7.75(2 \mathrm{H}, \mathrm{d}), 6.87-6.81(2 \mathrm{H}, \mathrm{d}), 4.29-4.26(4 \mathrm{H}, \mathrm{t}), 3.75-3.71(4 \mathrm{H}, \mathrm{t}), 2.33-2.26(4 \mathrm{H}, \mathrm{t}), 1.65-$ $1.20(60 \mathrm{H}, \mathrm{m}), 0.89-0.86(\mathrm{~J}=8 \mathrm{~Hz}, 6 \mathrm{H}, \mathrm{t}) \mathrm{m} / \mathrm{z}(\mathrm{ESI}): 742.2$

\section{(E)-2-(4-(bis(2-(stearoyloxy)ethyl)amino)styryl)-3-ethylbenzo[d]thiazol-3-ium iodide (4):}

A mixture of 3-ethyl-2-methylbenzothiazolium iodide $(152 \mathrm{mg}, 0.5 \mathrm{mmol})$ and ((4formylphenyl)azanediyl)bis(ethane-2,1-diyl) distearate (4a) $(371 \mathrm{mg}, 0.5 \mathrm{mmol}$ ) in $10 \mathrm{~mL}$ ethanol was refluxed for $6 \mathrm{~h}$. After cooling to room temperature, the solid precipitated was filtered and recrystallized in ethanol to give $200 \mathrm{mg}$ of dark red powder. (yield: $39 \%$ ) $\mathrm{H} \mathrm{NMR}\left(\mathrm{CDCl}_{3}\right)$ : $\delta /$ ppm: 8.07-8.05 (2.5H, d), 7.96-7.83 (2H, q), 7.75-7.68 (2.5H, m), 7.62-7.58 (1H, t), 6.82-6.80 (2H, d), 5.17-5.11 (J=8 Hz, 2H, q), 4.28-4.25 (J=4 Hz, 4H, q) 3.75-3.70 (J=4 Hz, 4H, q), 2.33-2.26 (4H, q), 1.62$1.54(6 \mathrm{H}, \mathrm{m}), 1.24-1.23(57 \mathrm{H}, \mathrm{m}), 0.89-0.86$ (J=8 Hz, 6H, t) m/z (ESI): 902.4 
${ }^{1} \mathrm{H}$ NMR spectra for SD 1, 2, 3 and 4:
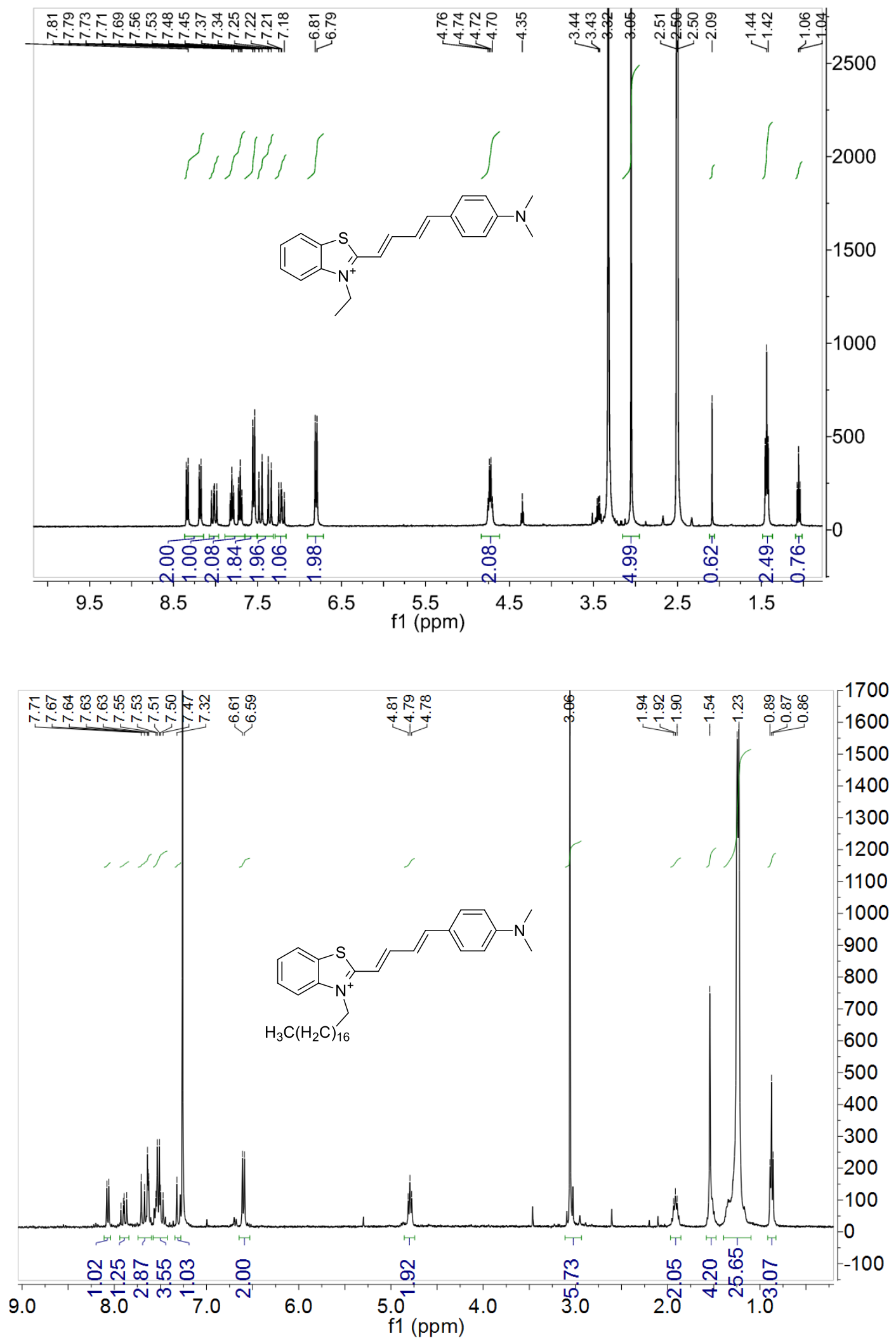

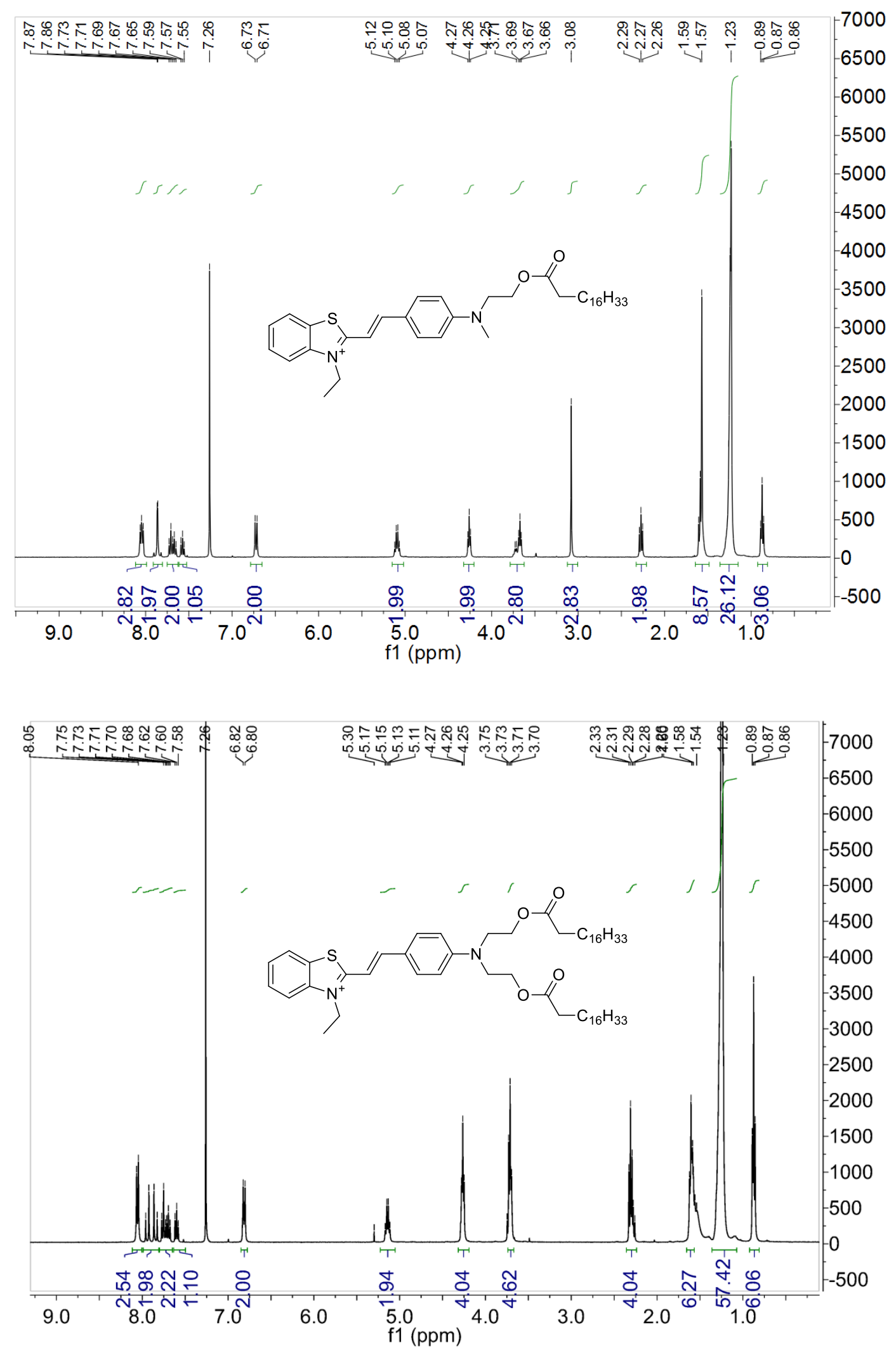
Mass Spectroscopy (Electrospray)for SDs 1, 2, 3 and 4:

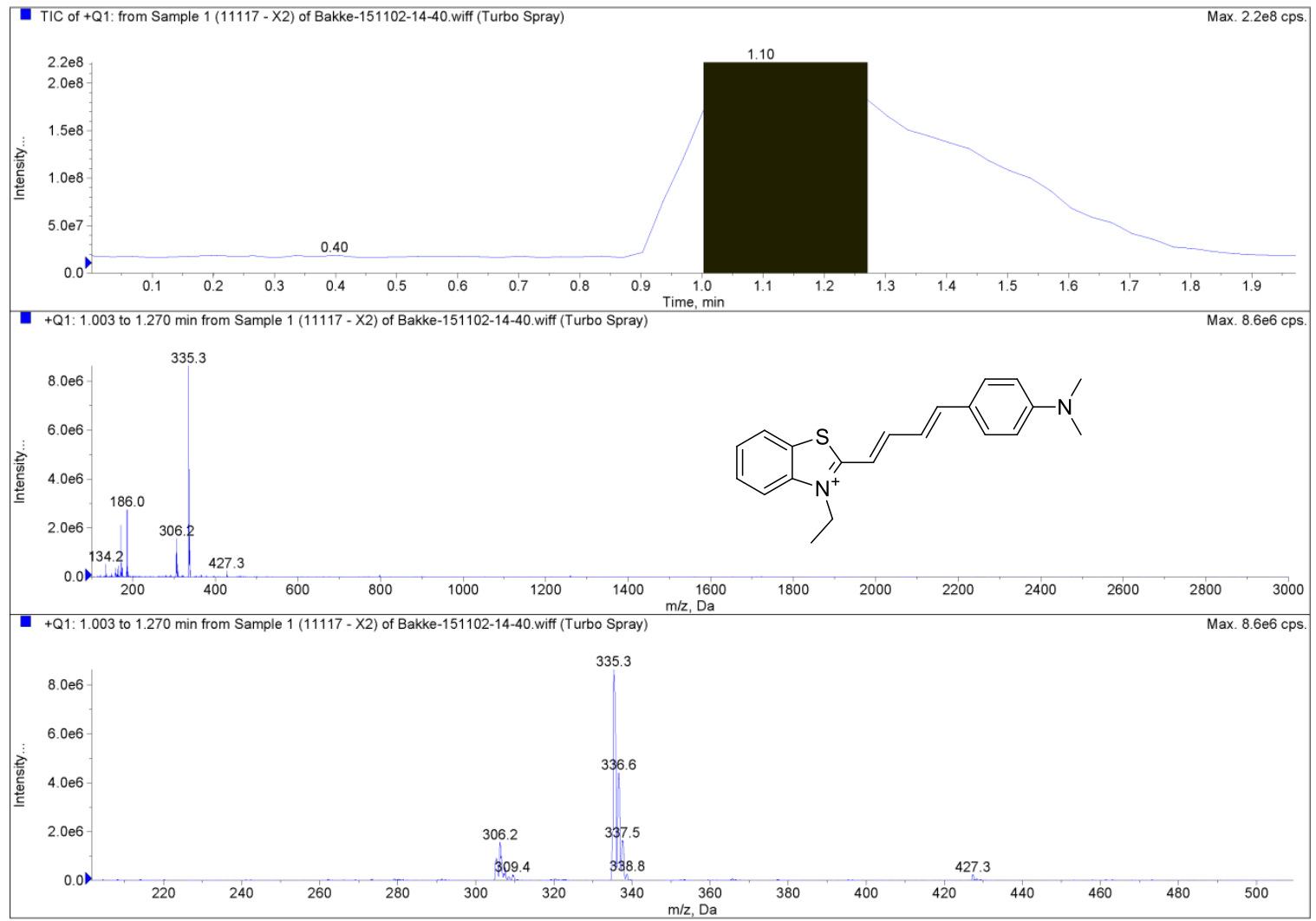

- TIC of +Q1: from Sample 1 (11117 - XC18) of Bakker-151102-11-21. wiff (Turbo Spray)

Max. $2.1 \mathrm{e} 8 \mathrm{cps}$

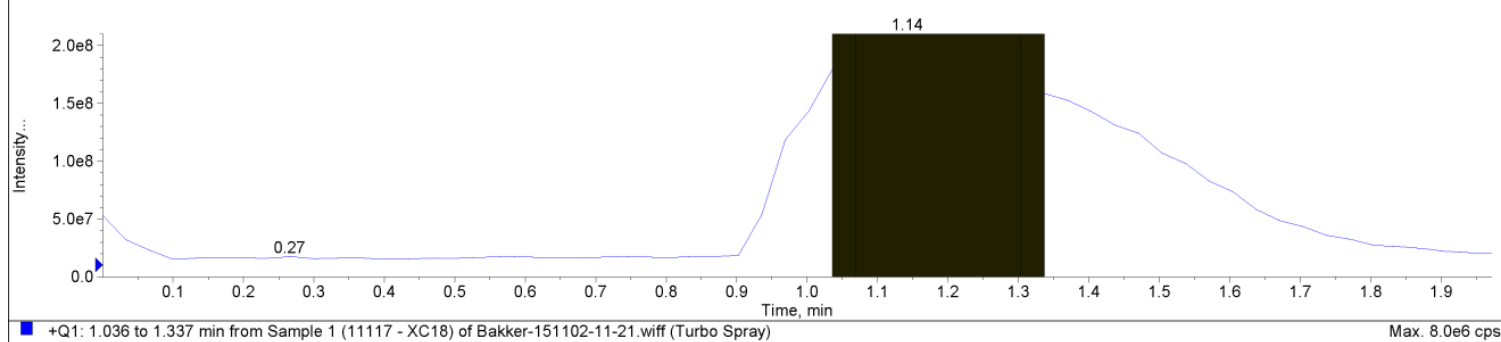

-Q1: 1.036 to 1.337 min from Sample 1 (11117 - XC18) of Bakker-151102-11-21.wiff (Turbo Spray)
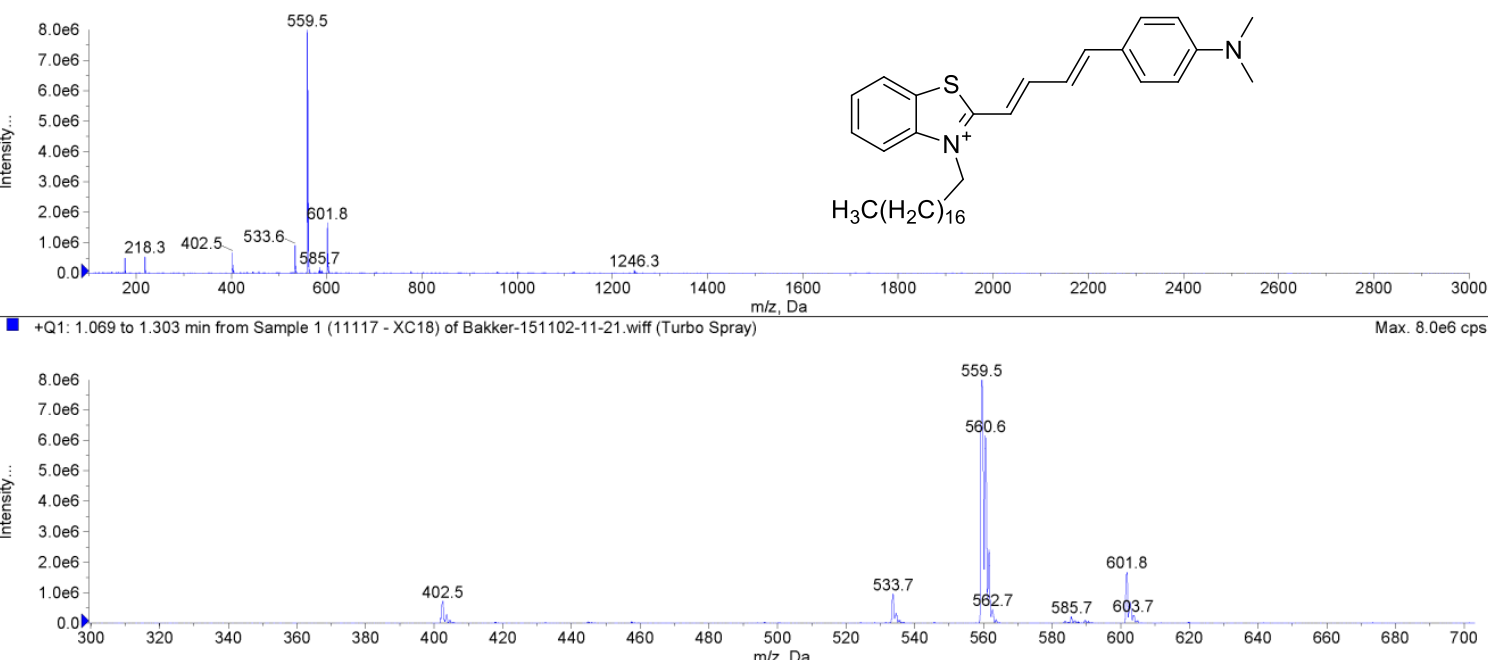

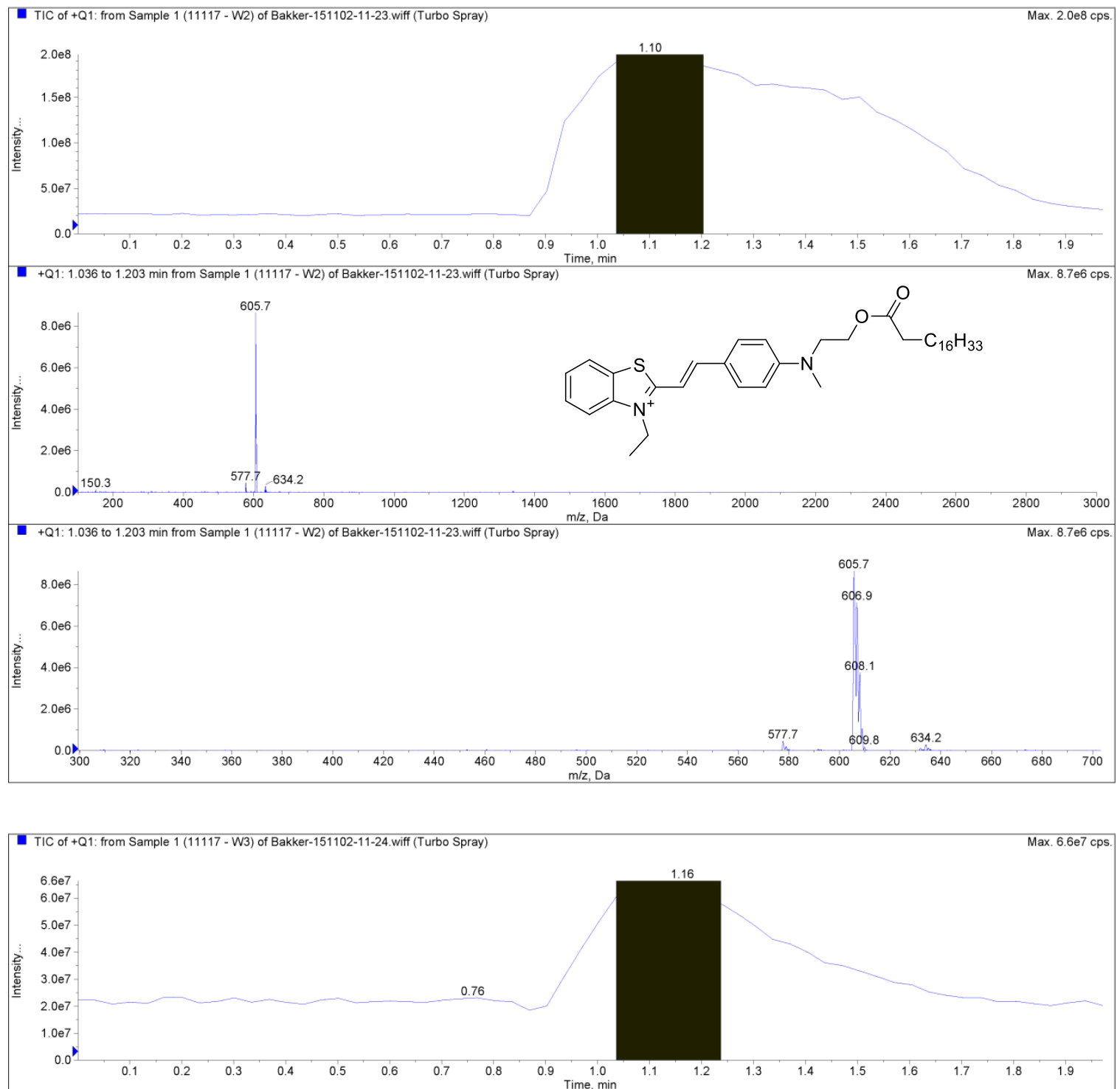

+Q1: 1.036 to 1.237 min from Sample 1 (11117 - W3) of Bakker-151102-11-24.wiff (Turbo Spray) Max. 3.6e6 cps.

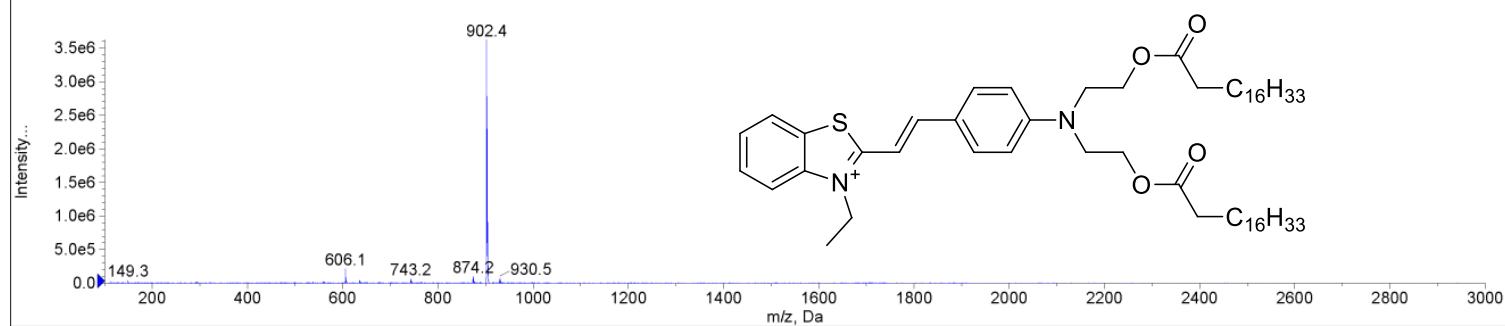

-QQ1: 1.036 to 1.237 min from Sample 1 (11117 - W3) of Bakker-151102-11-24. wiff (Turbo Spray) m/z, Da

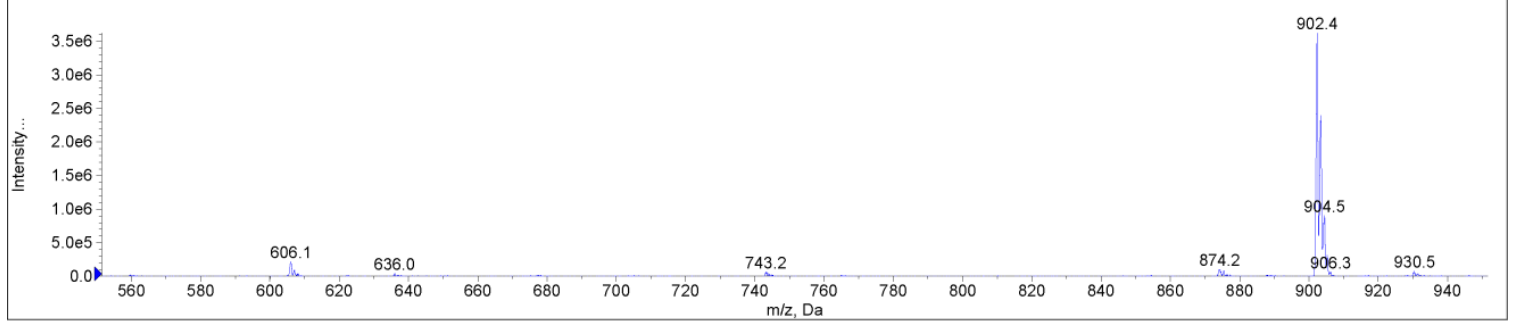


SD 2:

SD1:

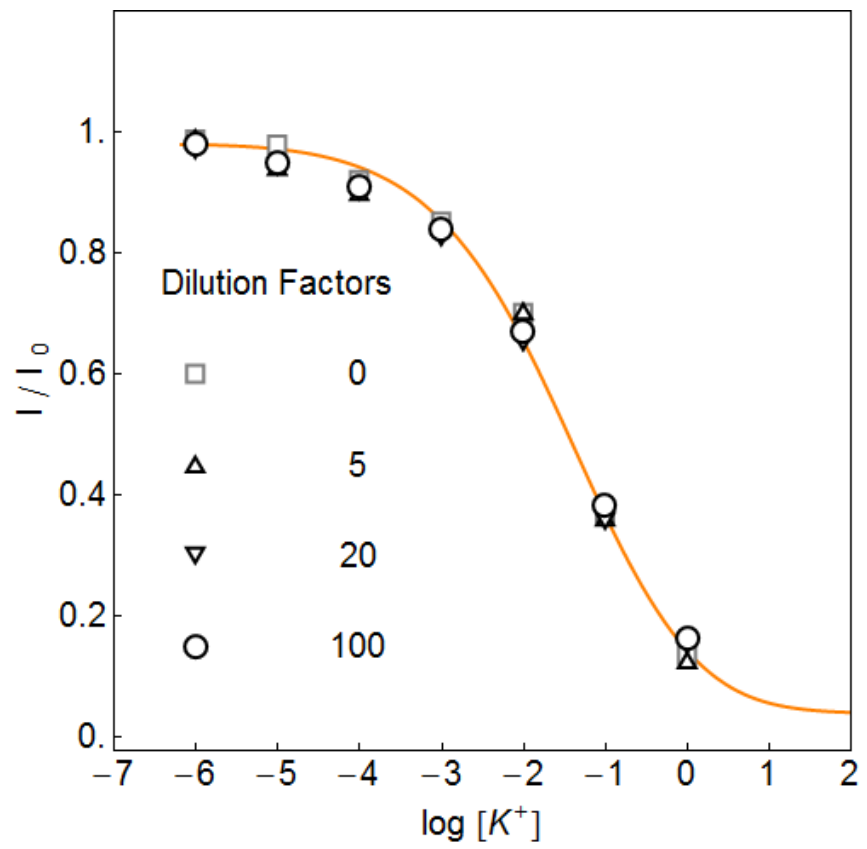

Figure S1. Fluorescence response to various K+ concentrations for nanosensors containing SD 2 upon various dilutions. $I_{0}$ is the maximum emission intensity in the absence of $\mathrm{K}$.
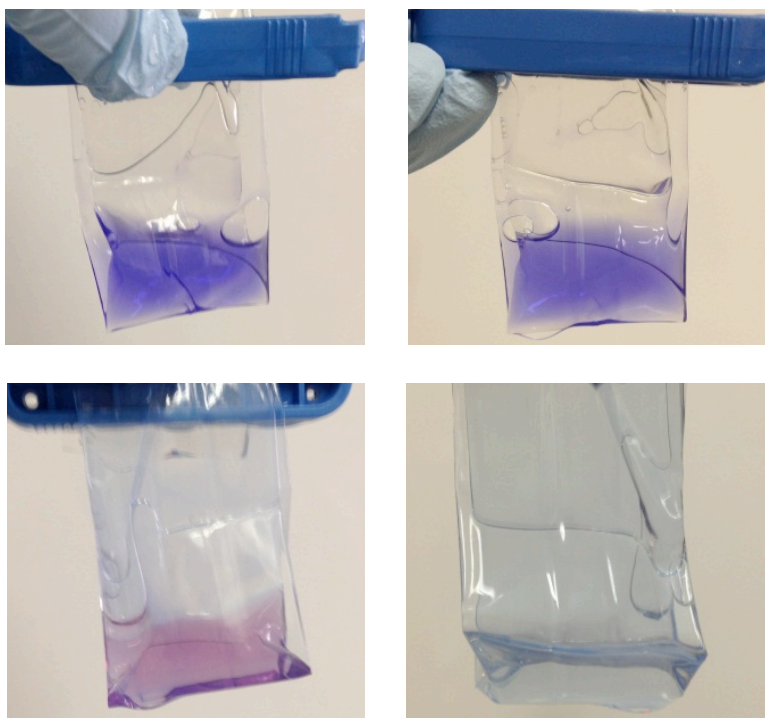

Figure S2. Images of the nanosensors incorporating SD 1 and 2 in dialysis tubing before after dialysis against $0.1 \mathrm{M} \mathrm{KCl}$ for 1 day. For SD 1 containing nanosensors, apparently the color became much weak due to the leakage of SD 1, while the color did not faint for SD 2 containing nanosensors confirming no severe dye leakage. 

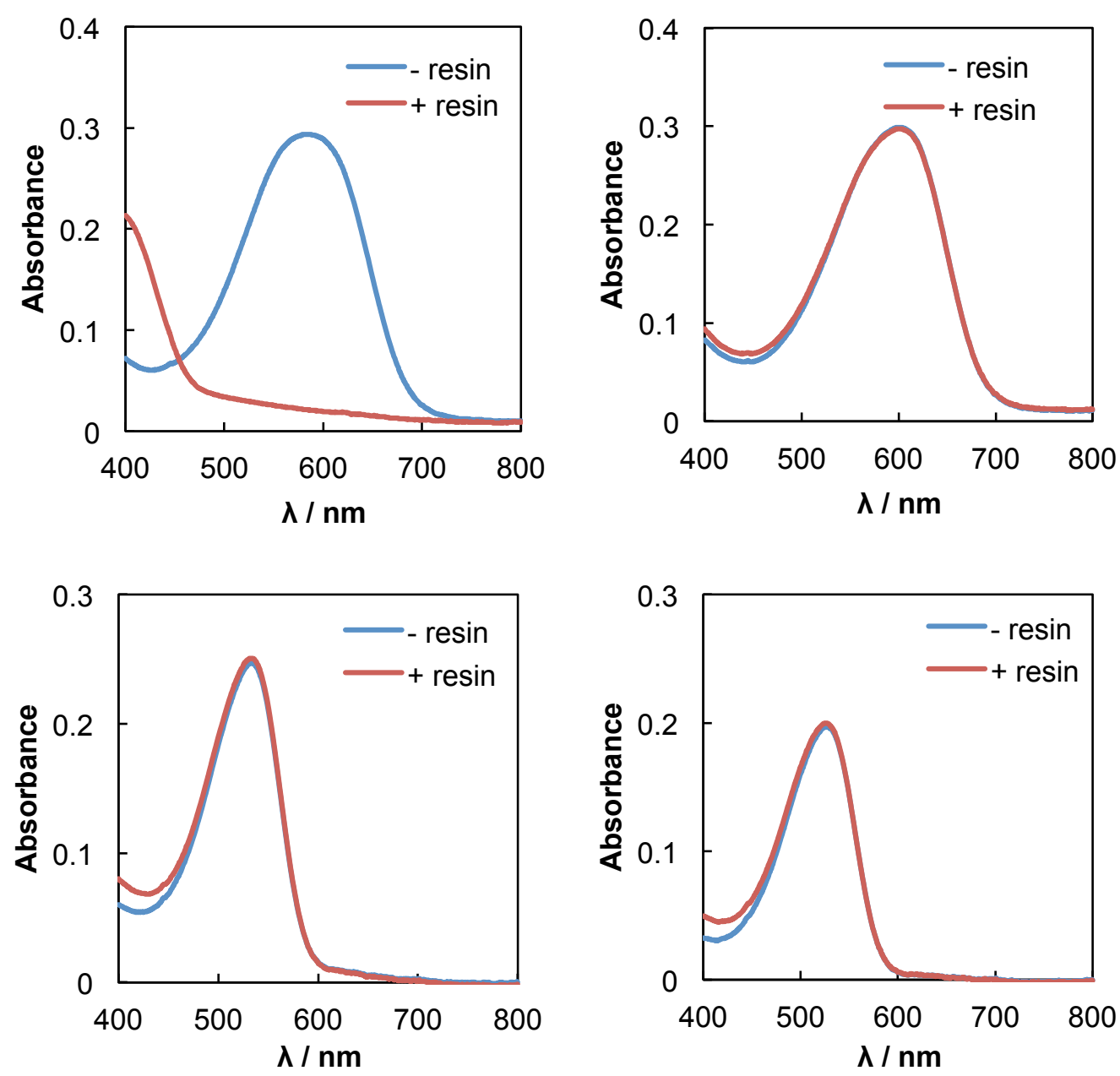

Figure S3. UV-visible absorption spectra of the nanosensors containing various SDs as indicated. The red traces were recorded from the nanosensors after exposure to cation exchange resin for $12 \mathrm{~h}(+\mathrm{resin})$. The blue traces were recorded from the nanosensors without exposure to cation exchange resin (- resin).

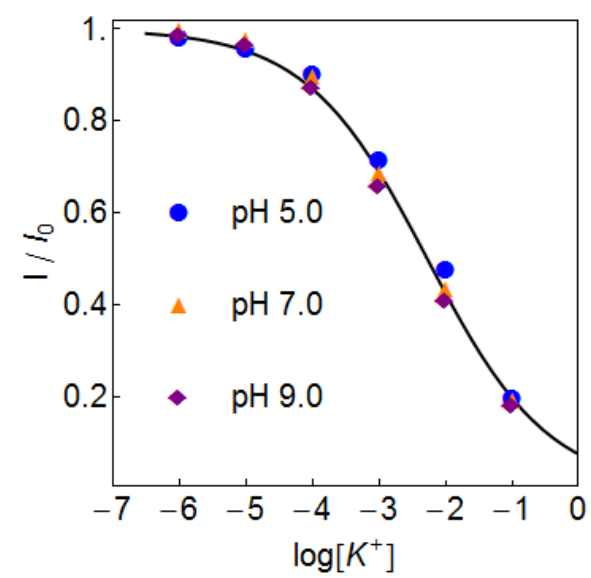

Figure S4. $\mathrm{K}$ responses of the nanosensors containing SD 2 measured in the fluorescence mode in phosphate buffers with different $\mathrm{pHs}$ as indicated. Signals were normalized according to the maximum emission intensity $\left(\mathrm{I}_{0}\right)$ in buffer solutions prior to addition of $\mathrm{KCl}$. 


\section{Appendix 1. Theoretical response for nanosensors containing water soluble SDs and influence of nanosensor loading (dilution effect)}

For a nanosphere containing water soluble SDs (D), ion exchanger $\mathrm{R}$ and ionophore (L) selective for the analyte $\mathrm{M}^{n+}$, the overall phase transfer equilibrium can be expressed as in Eqn. 1, with ns and aq designating the interior of the nanospheres and the surrounding aqueous phase, $\mathrm{p}$ being the complex formation stoichiometry and $\left(L_{p} M^{n+}\right)_{n s}$ being the formed adduct. Only the SDs distributed in the aqueous and organic phase are considered. The amount of the SDs at the interface is assumed to be very small.

$$
n D_{n s}^{+}+M_{a q}^{n+}+p L \stackrel{K 1}{\rightleftharpoons}\left(L_{p} M^{n+}\right)_{n s}+n D_{a q}^{+}
$$

The equilibrium constant $K 1$ is expressed in Eqn. 2.

$$
K 1=\frac{\left[\left(L_{p} M^{n+}\right)_{n s}\right]\left[D_{a q}^{+}\right]^{n}}{[L]^{p}\left[M_{a q}^{n+}\right]\left[D_{n s}^{+}\right]^{n}}
$$

Within the nanospheres, it is reasonable to assume that the number of total negative charges is equal to the number of total positive charges. This charge balance is expressed in Eqn. 3, where $V_{\text {w }}$ is the volume of the nanospheres and $n_{R}$-.is the number of moles of the ion exchanger.

$$
n_{R^{-}}=\left(\left[D_{n s}^{+}\right]+n\left[\left(L_{p} M^{n+}\right)_{n s}\right]\right) V_{n s}
$$

The mass conservation for the ionophore can be expressed with Eqn. 4 and 5, respectively, with $n_{t}$ and $n_{0}+$ being the number of moles of the ionophore and SDs, respectively.

$$
\begin{aligned}
& n_{L}=\left([L]+p\left[\left(L_{p} M^{n+}\right)_{n s}\right]\right) V_{n s} \\
& n_{D^{+}}=\left[D_{n s}^{+}\right] V_{n s}+\left[D_{a q}^{+}\right] V_{a q}
\end{aligned}
$$

As expressed in Eqn. 6, the fluorescence emission insensity (FL) encompasses the contribution from the organic nanosphere phase and the aqueous phase. $\varepsilon_{n,} \varepsilon_{n,}, \varphi_{n s}$ and $\varphi_{4}$ are the molar extinction coefficient and quantum yield of the SDs in the nanospheres and the aqueous phase, respectively. $I$ is the light intensity and $b$ is the light path length.

$$
F L=\sum_{\text {phase } \mathrm{i}}\left(\left[D_{i}^{+}\right] \times V_{i} \times \varepsilon_{i} \times I \times \phi_{i} / b\right)=I / b\left(\left[D_{n s}^{+}\right] V_{n s} \varepsilon_{n s} \phi_{n s}+\left[D_{a q}^{+}\right] V_{a q} \varepsilon_{a q} \phi_{a q}\right)
$$

The brightness of the SDs is much higher in the nonpolar nanospheric core than in the polar aqueous solution. Therefore, one can assume a relationship between the brightness of the solvatochromic dyes in the two phases, as expressed in Eqn. 7, where $\mathrm{x}$ is the ratio between the brightness.

$$
x \varepsilon_{n s} \phi_{n s}=\varepsilon_{a q} \phi_{a q}
$$

Since relative fluorescence emission intensity is measured in practice, now we can simplify Eqn. 6 by inserting Eqn. 7 to get Eqn. 8, where $\mathrm{F}$ is the relative emission intensity. 


$$
F=\left[D_{n s}^{+}\right] V_{n s}+x\left[D_{a q}^{+}\right] V_{a q}
$$

Now, a relationship between the analyte concentration in the aqueous sample and the relative emission intensity can be established by solving Eqn. 2, 3, 4, 5 and 8 . This relationship is expressed in Eqn. 9.

$$
\begin{gathered}
{\left[M_{a q}^{n+}\right]=\frac{\left(F+n_{R^{-}}(x-1)-x n_{D^{+}}\right)}{K_{2} n V_{n s}(x-1)}\left(\frac{F-n_{D^{+}}}{V_{a q}(x-1)}\right)^{n}\left(\frac{F-x n_{D^{+}}}{V_{n s}(1-x)}\right)^{-n}} \\
\left\{\frac{n_{D^{+}} p-n_{R^{-}} p+n_{L} V_{n s} n+\frac{p\left(n_{D^{+}}-F\right)}{x-1}}{n V_{n s}}\right\}^{-p}
\end{gathered}
$$

From this model, the relationship between the analyte concentration and $\mathrm{F}$ also depends on the ratio between the volume of the aqueous phase $\left(\mathrm{V}_{\mathrm{sa}}\right)$ and the volume of the nanospheres $\left(\mathrm{V}_{\mathrm{m}}\right)$.

Figure S5 shows the theoretical sensor response curves modelled from Eqn. 9 for monovalent ions. Apparently, the calibration curves will be shifted to the lower the detection limit when the loading $\left(\mathrm{V}_{\mathrm{n}}\right)$ is reduced, i.e., the nanosensors are diluted.

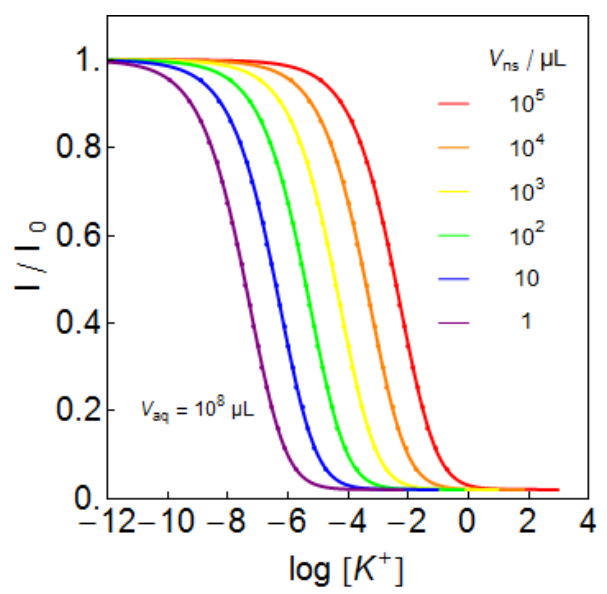

Figure S5. Theoretical nanosensor response for a monovalent ion $K^{+}$modelled by Eqn. 9 using different volume of the nanospheres and fixed volume of the aqueous phase as indicated. $\mathrm{I}_{0}$ is the maximum emission intensity determined in the absence of $\mathrm{K}$. Other Parameters: $n_{\mathrm{R}}-=1 \mu \mathrm{mol}, n_{L}=2 \mu \mathrm{mol}, n_{D}+=1 \mu \mathrm{mol}, \mathrm{K} 1=0.1$, $\mathrm{x}=0.02, \mathrm{p}=1$.

For a certain analyte concentration $(1 \mathrm{mM} \mathrm{K})$, the influence of the volume ratio $\left(\mathrm{V}_{\mathrm{as}} / \mathrm{V}_{\mathrm{m}}\right)$ on the sensor response $\left(\mathrm{I} / \mathrm{I}_{0}\right)$ is shown in Figure S6. For a certain concentration of $\mathrm{K}$, there is an optimal volume ratio where the sensor response is ca. 0.5. This fact can be taken advantage of when devising in vitro assays for a certain level of analyte to ensure that the sensor has the optimal sensitivity in the interested analyte concentration range. On the other hand, in the cases where the sample volume or the nanosensor volume is not known or difficult to determine, such as intracellular application, the concentration of the analyte becomes difficult to retrieve since calibrations cannot be performed unless the volume ratio is known. 


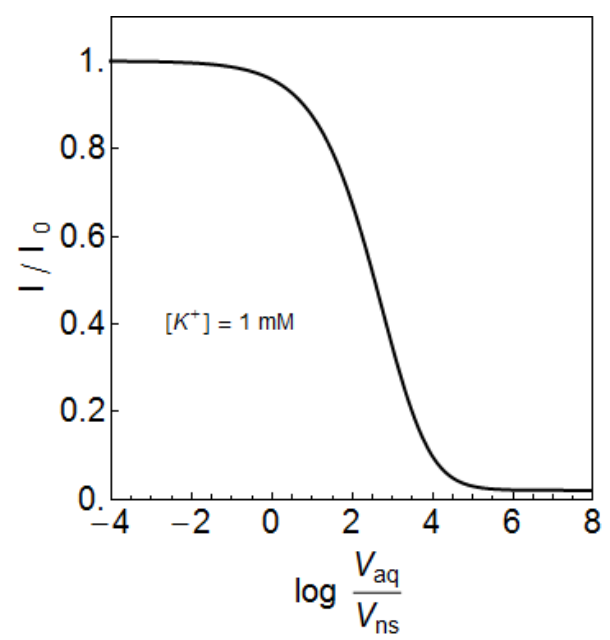

Figure S6. Nanosensor response $\left(\mathrm{I} / \mathrm{I}_{0}\right)$ at $1 \mathrm{mM} \mathrm{K}$ concentration as a function of the volume ratio between the aqueous sample and the nanospheres, where $I_{0}$ is the maximum emission intensity determined in the absence of K. Other Parameters: $n_{R^{-}}=1 \mu \mathrm{mol}, n_{L}=2 \mu \mathrm{mol}, n_{D}+=1 \mu \mathrm{mol}, \mathrm{K} 1=0.1, \mathrm{x}=0.02, \mathrm{p}=1$.

The second inference from this model is that the lipophilicity (reflected on the partition coefficient $\mathrm{K}$ of the SDs in both phases) of the SDs will influence the response range of the nanosensors. While $\mathrm{K}$ can be expressed with $\frac{\left[D_{a q}^{+}\right]}{\left[D_{n s}^{+}\right]}$, it is apparently associated with the overall equilibrium constant $\mathrm{K} 1$ as shown in Eqn. 2. To estimate the value of $\mathrm{K}$ in the nanosphere-water system, the theoretical partition coefficient for the SDs in octanol and water modelled in ChemBioDraw (P) was applied in a previously established relationship as shown in Eqn. 10, where $a$ and $b$ are coefficients depending on the actual solvent environment. While the exact values of $\mathrm{a}$ and $\mathrm{b}$ are not known, one can approximate them with values determined in DOS plasticized poly(vinyl chloride) membranes and water $(a=0.4$ and $b=0.8)$.

$\log K=a \log P+b$

In that case, using the difference of $\log \mathrm{P}$ for SD 1 and SD 2 in octanol-water (8.5), the $\log \mathrm{K}$ was estimated to be 4.2. This means that the response range of SD 2 should be shifted to the higher $\mathrm{K}$. concentration direction for 4.3 units on the logarithm scale. However, the experimentally observed difference as shown in Figure 2 (a) was smaller (3.6 units). Between SD 1 and SD 4, the difference in $\log \mathrm{P}$ is about 17 . Therefore, $\operatorname{logK}$ equals to 7.6 , indicating a lower detection limit for $\mathrm{K}$ of ca. $1 \mathrm{M}$. However, experimentally it was not the case. As shown in Figure 3, the response window was from $1 \mu \mathrm{M}$ to $1 \mathrm{M}$ of $\mathrm{K}$. These observations indicate a difference in the underlying mechanism as will be developed in Appendix 2. 


\section{Appendix 2. Theoretical response for nanosensors containing lipophilized SDs}

After attaching a lipophilic tail to the SDs, we assume that the SDs will now preferentially accumulate in the interfacial region with the charged chromophore poked into the aqueous phase after the analyte ions $\mathrm{M}^{n+}$ get extracted into the nanospheres. The solubility of the dyes in water is so low that the bulk distribution of the SDs in the aqueous phase can now be neglected. Therefore, the overall phase transfer equilibrium can be expressed with Eqn. 10, where $p$ is the complex formation stoichiometry and $\left(L_{p} M^{n+}\right)_{n s}$ is the formed adduct.

$n D_{n s}^{+}+M_{a q}^{n+}+p L \stackrel{K 2}{\rightleftharpoons}\left(L_{p} M^{n+}\right)_{n s}+n D_{s u}^{+}$

The equilibrium constant $\mathrm{K} 2$ is expressed in Eqn. 11, while $\left[D_{s u}^{+}\right]$and $n_{D_{s u}^{+}}$are the surface concentration and the total number of moles of the SDs on the surface as shown in Eqn. 12.

$K 2=\frac{\left[\left(L_{p} M^{n+}\right)_{n s}\right]\left[D_{s u}^{+}\right]^{n}}{[L]^{p}\left[M_{a q}^{n+}\right]\left[D_{n s}^{+}\right]^{n}}$
$\left[D_{s u}^{+}\right]=\frac{n_{D_{s u}^{+}}}{S}=\frac{n_{D_{s u}^{+}}}{4 \pi r^{2}}$

Similar with previous derivation, the mass conservation for the SDs can be expressed in Eqn. 13:

$n_{D^{+}}=4 \pi r^{2}\left[D_{s u}^{+}\right]+\frac{4}{3} \pi r^{3}\left[D_{n s}^{+}\right]$

The mass conservation for the ionophore can be expressed in Eqn. 14:

$n_{L}=\frac{4}{3} \pi \mathrm{r}^{3}\left([L]+p\left[\left(L_{p} M^{n+}\right)_{n s}\right]\right)$

The charge balance in the interior of the nanospheres can be expressed in Eqn. 15:

$n_{R^{-}}=\left(\left[D_{n s}^{+}\right]+n\left[\left(L_{p} M^{n+}\right)_{n s}\right]\right) V_{n s}=\left(\left[D_{n s}^{+}\right]+n\left[\left(L_{p} M^{n+}\right)_{n s}\right]\right) \frac{4}{3} \pi r^{3}$

Represented by Eqn. 16, the relative fluorescence emission intensity can be obtained considering an excitation light intensity I, light path length $b$.

$F L=I / b\left(\left[D_{n s}^{+}\right] \frac{4}{3} \pi r^{3} \varepsilon_{n s} \phi_{n s}+\left[D_{s u}^{+}\right] 4 \pi r^{2} \varepsilon_{s u} \phi_{s u}\right)$

The brightness of the SDs located in the interfacial region should be much smaller compared with those in the interior of the nanospheres. Assuming a ratio of $y$ for the brightnesses, a simplified relative emission intensity $\mathrm{F}$ is expressed in Eqn. 17.

$F=\frac{1}{3}\left[D_{n s}^{+}\right] r^{3}+y\left[D_{s u}^{+}\right] r^{2}$ 
Therefore, the relationship between $\left[M_{a q}^{n+}\right]$ and F can be solved from Eqn. 11, 12, 13, 14, 15 and 17 to give Eqn. 18.

$$
\begin{aligned}
{\left[M_{a q}^{n+}\right]=} & \frac{3^{1-n-p}(4 \pi)^{p-1}}{K 2 \cdot n \cdot r^{3}(y-1)}\left(F+n_{R^{-}}(x-1)-x \cdot n_{D^{+}}\right)\left(\frac{r\left(F-n_{D^{+}}\right)}{x \cdot n_{D^{+}}-F}\right)^{n} \\
& \left(\frac{n_{L}+\frac{p\left(n_{R^{-}}-F-x \cdot n_{R^{-}}+x \cdot n_{D^{+}}\right)}{n(x-1)}}{r^{3}}\right)^{-p}
\end{aligned}
$$

The theoretical response derived from Eqn. 18 also exhibits sigmoidal shape. Now the sensor response no longer depends on the volume of the aqueous sample. The radius of the nanospheres will affect the sensor response. However, the radius can be measured beforehand and its influence is relatively small. Most importantly, the calibration of the sensor response can now be used without concerns from the dilution effect. 


\section{FRET efficiency $(E)$, the overlap integral $(J)$, Förster distance $\left(R_{0}\right)$ and distance between adjacent donor Lumogen Red and acceptor SD $2\left(R_{\mathrm{DA}}\right)$.}

The FRET efficiency E is defined by Eqn. 19.2

$$
E=\frac{R_{0}^{6}}{R_{0}^{6}+r^{6}}
$$

$\mathrm{R}_{\mathrm{v}}$ is the Förster distance ${ }^{2}$ at which $\mathrm{E}=50 \% . \kappa$ is the orientation factor between the dipoles of the donor emission and the acceptor absorption. A typical value of $2 / 3$ is used here for $\kappa^{2} . \mathrm{n}$ is the refractive index $\left(\mathrm{n}=1.450\right.$ for DOS at $\left.20^{\circ} \mathrm{C}\right)$.

$$
R_{0}=0.211 \cdot\left\{\kappa^{2} \cdot n^{-4} \cdot J\right\}^{1 / 6}
$$

The overlap integral ${ }^{2}$ is calculated according to Eqn. 21, where $\lambda$ is the wavelength, $\varphi_{v}$ is the quantum yield of Lumogen Red $(90 \%), \varepsilon_{a}$ is the molar absorptivity of SD 2, $\mathrm{f}_{\mathrm{o}}(\lambda)$ is the normalized emission spectrum of Lumogen Red and $\mathrm{f}_{A}(\lambda)$ is the absorption spectrum of SD 2 normalized according to maximum absorptivity.

$$
J=\phi_{D} \cdot \varepsilon_{A} \frac{\int_{0}^{\infty} f_{D}(\lambda) f_{A}(\lambda) \lambda^{4} d \lambda}{\int_{0}^{\infty} f_{D}(\lambda) d \lambda}
$$

The average distance between adjacent donor and acceptor $\left(R_{\mathrm{D}}\right)$ in the nanospheres is estimated by assuming even distribution of the dye molecules. The density of the nanospheres was $1 \mathrm{~g} \mathrm{~mL}$ given the fact that nanosensors remain a clear suspension even after several months. A total mass of $14.7 \mathrm{mg}$ then corresponds to $14.7 \mu \mathrm{L}$ in which evenly distributes $1.57 \times 10^{\prime \prime}$ donor and $1.38 \times 10^{\text {n }}$ acceptor. $R_{\triangleright \wedge}$ was estimated to be ca. $0.2 \mathrm{~nm}$. Admittedly, this is only a rough estimation and the volumes of the molecules themselves were not taken into account. Nevertheless, it suffices to show that $R_{\triangleright \wedge}$ is much smaller than $R_{\text {。 }}$.

\section{References}

1. Bakker, E.; Lerchi, M.; Rosatzin, T.; Rusterholz, B.; Simon, W., Synthesis and characterization of neutral hydrogen ion-selective chromoionophores for use in bulk optodes. Anal. Chim. Acta 1993, 278, 211-225.

2. Sun, Y.; Rombola, C.; Jyothikumar, V.; Periasamy, A., Forster resonance energy transfer microscopy and spectroscopy for localizing protein-protein interactions in living cells. Cytometry Part A 2013, 83A, 780-793.

3. Reith, H.; Eckardt, H., Preparation and physical-chemical investigation of homologous series of dicarboxylates with special consideration of their use as lubricants. Freiberger Forschungshefte A 1962, 250, 39-86. 